\title{
The Analysis of Local Government Interests in the Execution of
}

\author{
Public Policy
}

\author{
Guo Xinyu' ${ }^{1}$, Zhang Yinsong ${ }^{2}$ \\ ${ }^{1}$ School of Public Management, Yunnan University of Economics and Finance, ${ }^{2}$ School of Foreign \\ Languages, Yunnan Agricultural University, Kunming, P.R. China, 650201 \\ (E-mail:gxy0871@163.com; E-mail:zhangyinsong74@yahoo.com.cn)
}

\begin{abstract}
Being the implementing course of bringing the public policy from conceptual condition into reality, the public policy execution plays a direct and key role in the policy performance. In the public policy execution, the difference of value choice is recreated in the central policy, causing the deviation and failure of public policy execution due to the interests of local governments independent of the public interests on the basis of the interests of themselves. The "edge ball" of the policy is the typical reflection which the local governments interests impact the central policy execution. To guarantee the final achievement of policy objectives, various measures are necessary to get rid of the negative impact on policy execution caused by the action of principal parts of local interests.
\end{abstract}

Keywords: Interests of Local Governments; Public Policy Execution; Governmental Control of Interests

\section{Introduction}

Public policy is the basic means of resolving the social public problems by the government and the general name for all the regulations and norms formulated by the government to direct the actions of principal parts. The solution of all the social issues such as poverty, unemployment and ecological deterioration in contemporary China which is in the period of social transformation relies heavily on the relevant policy effectively formulated and fairly executed by the government. However, the public are not satisfied with the solution of many social public issues to the utmost degree. Is it due to the policy itself made by the government to solve the problem or to the deviation of the execution of the public policy? Admittedly, there are problems in the policy and there are even more in the policy execution. Allison, American expert of policy put forward that "in the course of achieving the policy objectives, the definite function of plan only accounts for $10 \%$ while the effective execution accounts for the other $90 \%$." The policy execution has the decisive effect on the real result of the policy.

Local governments always have their own ways in dealing with central policy. So it is practically significant to study the reason for the deviation of the central policy execution by the local government and the way to overcome the negative factors in the central policy execution by the local government so as to guarantee the universal, effective and fair execution of the central policy.

\section{The Relationship between Public Policy Execution and Interests}

Interests refer to the scarce resources occupied by the principal parts of interests to meet their demands. Serving as the basis of social life, interests are the mere and universal driving force for the social development and the root of social contradictions in social life, from which all the complex social phenomena can be explained. As the course of authoritative distribution of limited social resources by the government with the public power, the public policy execution is essentially the authoritative distribution of social public interests. Therefore, interests are the core of public policy. A series of issues such as distribution, increase and balance of interests decided by the nature of policy which go through the course of the policy exist in the policy execution which is the main part of the policy course.

In the policy execution process, every participant observes the principle of maximizing interests and minimizing the losses to the utmost degree. The principal part of policy execution carries out the cost-profit analysis in the policy 
execution course. If there is some gap between the actual profit and the anticipative one or between the profit of its own and that of others, the feeling of being deprived of the interests will appear, which will directly triggers various actions of deviation of policy execution from the policy objectives. All the principal parts of execution strive for the maximum benefit of the policy and the minimum loss as much as possible, which finally leads to form the filtering mechanism of interests between formulator and executor of the policy. The executor always regards the local or individual interests as the countermeasure parameter, executing the policy according to the profit of the policy or even parochially protecting the local or individual interests with the power.

\section{The Form of the Interests of Local Governments}

In reality, as the regional governments of all levels which govern some areas of the state, the local governments, on the one hand, best represent the local public will and the public interests; on the other hand, they are the special groups of interests which are different from those of other social organizations due to their special position and function in the social structure, which makes the interests of local governments different from the public interests they represent. The governmental policy should be on behalf of the public interests, but the public policy execution deviates from the public interests because of the penetration of the interests of local governments, which can be shown in three aspects as follow:

\subsection{The Little Group Interests of Local Governments and Governmental Departments}

The local governments and governmental departments have more power in the market economy because of the decentralization reform and the devolution of administrative power to lower levels. Thus, the position of interest principal part of the local governments and governmental departments is accentuated and the identity of "economic man" of local governments and governmental departments is strengthened, leading to the game between the local governments and governmental departments and central government in the process of the formulation and execution of the policy: for one thing, the local governments bargain with the central government or upper governments on the issue of interests distribution, which makes it difficult to pass some policy options.

For another, the local interests are placed above the overall interests. And the local governments formulate the policy with the countermeasure parameter of local interests, pursuing the maximization of interests of departments or regions they governed regardless of the macro and overall interests, which harms the interests of the majority of the people in our country.

\subsection{The Special Interests of the Whole Local Governments}

The local governments also have the interest pursuit of their own. On the one hand, the maximization of the scale of the government is pursued. The budget scale of the government is directly in proportion to the governmental power, namely, the more governmental budget is, the more power the government has and the more social resources this institution possesses. The increasing number of the staff and the growth of the non-productive expense make the government overstaffing and lower efficiency of formulation and execution of the policy. On the other hand, the increasing department expense is sought. The government undertakes the function of providing the public goods regardless of the cost, which creates enough room for the expense expansion of the government.

\subsection{The Individual Interests of the Local Government Officials}

The individual interests of the local government officials are actually the basic parts of the whole interests of local governments. As a matter of fact, local government officials are faced with the role conflict between being "a civil servant" and being "a common member of the society". The theory of public choice shows that the interests demand and choice of the governmental officials do not change in accordance with the change of their role. That is to say, the governmental officials still have the motive to seek the private gains in exercising their power, which can be shown in the following aspects. Firstly, the policy execution is wrested to seek political interests. In the current system of cadre assessment of our country, the increasing output value and the new construction projects in their years of the office are the key standard to evaluate the achievements of the cadres. In other word, "judging cadres with figures and chasing figures by cadres in return.” Consequently, to win the favor and support of the superior and the people and to maximize the political interests, the governmental officials selectively execute the policy which is good for acquiring the public favor and support and promoting their image and put aside or wrest the execution of other policies. Secondly, the policy execution is wrested in pursuit of economic interests. Many governmental officials wantonly trade power for 
money to seek economic interests in the name of the interests of the government and state, resulting in corruption and rent-seeking. James Mill stressed: "undoubtedly, if it is possible to entitle the power to a group of so called representatives, they will seek the interests of their own with the power instead of social interests like anyone else.”

The three aspects mentioned above are the specific ground for the strategic choice made by the local governments in the policy execution.

\section{Analysis of Public Policy Execution under the Influence of Interests of Local Governments}

To analyze the change of policy execution of local governments under the influence of the interests of local governments, let us take the typical "edge ball” for example: according to the definition of Zhou Zhenhua, "as the policy executor, the grass root organization will seek the chance of regaining from the unbalancing structure of policy system and maximization of the effect in the policy execution, take advantage of the contradiction between the new policy and the old one." This game phenomenon is called playing the "edge ball" of policy. Firstly, to maximize the local interests as much as possible by means of introducing foreign capital or increasing the local finance, the current policy is made full use, namely, obtaining no less than the "deserving profit". Secondly, according to the principle of local interests, the loopholes of new and old policies are sought to maximize the interests by means of taking advantage of favorable points of the new and old policies while attributing the cost and burden to the old policy. Thirdly, the policy is moderately applied in accordance with the policy spirit on the edge of the permitted range of central government. Here "moderate" implies the art of policy application: maximize the marginal profit of the policy while avoid challenging the authority of central policy so as to acquire the profit which is undeserving.

Different local interests are affected by different special policy which local governments get, different autonomy reformed and different execution of central policy. Therefore, under the background of system transformation, playing the "edge ball" of the policy execution will have a direct impact on the profitable condition of local interests. The policy execution and application of the local governments can be classified into three types: (1) positive execution of policy. The new policy is initiatively enjoyed as much as possible and condition is created for the sake of striving for other policy. (2) Conservative execution of policy. Just be content with the current existing policy. (3) Negative execution of policy. The new policy is not carefully studied and well applied. Different attitudes towards the policy execution lead to different action of policy execution and different profit. And the above phenomenon can be illustrated by the following chart:

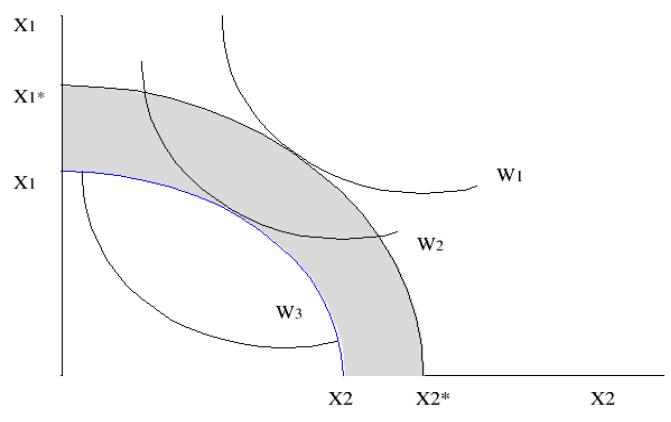

Figure 1

Suppose that policy application creates two kinds of profits (material profit as well as the sum of political profit and spiritual profit on the basis of material profit) which are represented by $\mathrm{X} 1$ and $\mathrm{X} 2$ respectively in the chart. If the total quantity of the policy resource is fixed, there may be a possible boundary of policy resource application. The effect combination on any point of this boundary shows the maximization of policy application of the fixed policy resource.
Due to the particularity of the policy adjustment in the system reform and the coexistence of new and old policies, the policy application is greatly elastic. Therefore, the possible boundary of policy application (the shadow band in the chart) is not a curve but a curve band consisted of $\mathrm{X} 1 \mathrm{X} 1 *$ and $\mathrm{X} 2 \mathrm{X} 2 *$. W1, W2 and $\mathrm{W} 3$ in the chart respectively represent three profit curves of policy application, in which $\mathrm{W} 1$ is the curve of making full use of the current policy and 
obtaining the maximized profit, representing the positive execution of policy; W2 is the curve of making good use of the current policy and obtaining the normal profit, representing the conservative execution of policy; W3 is the curve of abandoning the current policy and losing the profit, representing the negative execution of policy. The intersect area of this curve and X1X2 is the profit defect caused by the policy abandonment. In addition, no point on W3 surpasses X1X2.

The power devolution and interests distribution of the central government arouses unprecedentedly the interests awareness of all the regions of our country, but the financial and personnel power is divided arbitrarily between the central government and local governments and the necessary mechanism is lacked to restrain the interests of local governments due to a series of issues of faulty systematic standards in the period of system transformation. While "some areas are allowed to get rich first", corresponding mechanism is lacked to compensate the interests of other areas, which makes all the local governments to seek the interests realization and compensation in the policy execution at the lure of local interests without violating the central policy.

After receiving the central policy, the local governments understand the content of the policy according to the intention and objects of their own and the information collected. They also analyze the potential risk of executing the central policy with alteration according to their interests and the possible measures the central government may take. The decision judgment of policy execution as complete implementation in accordance with the central policy spirit, playing "edge ball” or seeking local interests in disguised form is made on that basis..

\section{The Control of Interests of Local Governments in Public Policy Execution}

To fundamentally improve the policy execution of local governments, the local interests should be effectively coordinated; the policy system and policy execution should be improved; the deviation of the public policy execution should be prevented.

Firstly, the central interests and local interests should be further integrated. In the actual process of resolving the interest contradiction between central government and local governments, their interest difference should be admitted and the equilibrium between the central government and local governments should be sought. The key of achieving the interest integration is to overcome the parochial localism and extreme individualism. The difference between the central interests and local interests should be admitted; the local interests should be subordinated to the central interests; the local governments, as the lower organization of central government, should obey and execute the central policy and decree; the central government should give consideration of the local interest demand in policy formulation. Because the politics and economics of all the areas of our country develop in an unbalance way and the interest demand of all the areas are different from each other. On the basis of unified government orders, the interest compensation should be taken into account to avoid the unfair interest distribution and intensifying inter-regional conflict of interests which will hinder the central policy execution. Meanwhile, consideration should also be given to the horizontal interest integration of interests among local governments and policy execution organizations. By means of this integration, the individual, local and state interests are rationally allocated so as to avoid the failure of policy execution due to the interest conflict.

Secondly, the controlling ability of the central government should be strengthened. The powerful ability of controlling is indispensible in the effective execution of the macro-policy of the central government. In the policy execution, the power centre which has a mighty controlling ability in the range of the whole country can not only win the necessary authority to strictly enforce orders and prohibitions but also suppress the swelling of the local governments, reducing the resistance of the policy execution organizations and policy objectives(target groups) to the decision-making organizations. Then, the power devolution from the central government to local governments should be legalized and institutionalized. Centralization dose not mean the reclamation of all the local power. Instead, the policy power of central and local government should be specifically defined and the power should be distributed and devoluted rationally and orderly to prevent unfair interest distribution and disobedience with more power.

Thirdly, the restrain mechanism of interests of local governments should be improved. The systematic restrain is of top importance. The interest relationship between central government and local governments should be explicitly defined through the system of the Constitution and laws, making the regulation of interest relationship between different levels have the laws to abide by so as to guarantee the transparency and stability of the interest regulation. Then it follows the supervision restrain. The state should carry out a series of relevant laws and regulations on the aspects of 
supervision of policy execution to guard against the "deviation" of policy execution due to the game between the principal parts of interests; the supervision mechanism should be improved by means of giving full play to the party committee, NPC, CPPCC, discipline inspection departments and news media in supervision so as to supervise every key link of the policy execution, to prevent false supervision and omitting supervision, and to guarantee the transparency of the policy execution, making the governmental interests in high accordance with the interests of the people and state. The responsibility restrain is also of high importance. Establishing the effective responsibility system to make the executing parts shoulder the administrative responsibility of policy execution is the powerful inner mechanism of restrain which prevents the executor from being deviate from the policy objectives on the basis of parochial interests. Last but not least, the punishment on the mistake policy execution should be strengthened. Those who violate the central policy, impair the central authority and make severe mistakes in policy execution should be strictly investigated and punished in accordance with laws and disciplines. And the heads of party or government who are slack in halting the local or department protectionism can be recalled by the one-vote-veto system.

Fourthly, the policy execution system of marketization should be implemented. The main tendency of western administrative reform is marketization of governmental function and introduction of competition mechanism, incentive mechanism and supervision mechanism of the market into the government to enhance the management efficiency and profit of the government. The marketization of the policy execution is to evaluate the policy execution result according to the realization of policy objectives instead of resource investment in the policy execution process and to encourage politically and economically executors at all levels to compete with each other in policy execution effect. Non-governmental departments can be made selectively to execute policy to achieve the separation of policy execution from formulation, since the main duty of the government is to supervise the policy execution, safeguard the public interests and maintain the social order.

\section{Conclusions}

The analysis on governments interests in public policy activity is due to a real background of our country, need to excavate its realistic reason produced, and make the corresponding countermeasure, interests of government making public interests can be satisfied and rational too in case of getting the biggest embodiment.

\section{References}

[1] Wang Fusheng. The Research on Policy. Sichuan People's Press. 1991

[2] Gao Qingnian. The Self-Benefit and Legal Control of the Government. Exploration. 2000, (1)

[3] James Mill: The Theory of Public Choice, Beijing, China Social Sciences Press (1999)

[4] Wang Yuming. The Reason and Prevention of Public out of Control [J]. Lingnan Journal, 1999, (4)

[5] Li Xue. The Analysis of Governmental Interests of Public Policy [J]. Administrative Forum, 2001, (10)

[6] Chen Zhenming. Public Policy [M] Beijing: China Renmin University Press, 1998

[7] Tu Xiaofang. The Impact of Governmental Interests on Governmental Behavior. China Administrative Management, 2002, (10)

[8] Liu Yurong, Ding Mingjie. The Impact and Countermeasure of Governmental Interests on Policy Execution. Journal of Hubei Administrative College, 2003, (1) 